\title{
The Role of Ratio Profits as The Improvement of Realization of KPR BTN Credit on PT. Bank Saving Country (Persero) Tbk.
}

\author{
Achmad Fauzi \\ University of BSI Bandung \\ achmad_fauzioke@yahoo.com
}

\begin{abstract}
Mortgages are used as credit services provided by banks to customers who want a special loan to meet the needs in the construction of houses or home renovations that must be in accordance with the procedures that have been specified as a condition of completeness of KPR. Data collection methods in the preparation of this research is a qualitative research method with one case study in calculating the profit generated by Bank BTN (Bank Tabungan Negara) can be calculated by using the ratio. One of the ratios used is the profitability ratio. In the ratio of profitability there are ratios such as: ROA (Return On Asset), ROE (Return On Equity), NIM (Net Interest Margin), and BOPO (Operational Cost). To find out the ROA (Return On Asset) ratio, net income after tax and income is required. As for calculating ROE (Return On Equity) ratio required net income after interest and taxes and capital. And for NIM (Net Interest Margin) ratio required total net profit after tax and income, while BOPO (Operational Cost) required operational and operational income. Analysis of financial statements is very important to do because at this stage the financial statements that have been calculated on the ratio already described, the ratio results obtained by PT. Bank BTN (Bank Tabungan Negara) may be decided to comply with the provisions of the BI standard provisions.
\end{abstract}

Keywords: Credit Realization, KPR, Rentability Ratio

\section{Pendahuluan}

Bank adalah badan usaha yang kekayaannya terutama dalam bentuk aset keuangan (financial assets) serta bermotif profit juga sosial, jadi bukan hanya mencari keuntungan saja (Hasibuan, 2005:2). Bank adalah suatu badan usaha yang tugas utamanya sebagai lembaga perantara keuangan (financial intermediaries), yang menyalurkan dana dari pihak yang berkelebihan dana (idle fund surplus unit) kepada pihak yang membutuhkan dana atau kekurangan dana (deficit unit) pada waktu yang ditentukan (Lukman, 2009:14). Bank dikenal sebagai lembaga keuangan yang kegiatan utamanya menerima simpanan giro, tabungan dan deposito. Kemudian bank juga dikenal sebagai tempat untuk meminjam uang (kredit) bagi masyarakat yang membutuhkannya (Kasmir, 2012:24).

Salah satu fungsi bank adalah menyalurkan kredit baik kepada perorangan maupun badan usaha. Pemerintah sangat mendorong, mendukung dan membantu kepada sector UKM (usaha Kecil Menengah atau istilah asing SME "Small Medium Entrerprise"), agar UKM menjadi penopang tatanan perekonomian Indonesia. Artinya Pemerintah menginginkan agar perekonomian Indonesia berkembang terutama melalui sector UKM (Maryanto, 2011:3). Kredit sebagai penyedia uang atau tagihan yang dapat dipersamakan dengan itu, berdasarkan persetujuan atau kesepakatan pinjam-meminjam antara bank dengan pihak peminjam untuk melunasi utangnya 
setelah jangka waktu tertentu dengan pemberian bunga. Menurut Sigit dan Totok (2006:114) Kredit nasabah berdasarkan kemampuan untuk melaksanakan suatu pembelian atau mengadakan suatu pinjaman dengan suatu janji pembayarannya akan dilakukan pada suatu jangka waktu yang disepakati". Kredit merupakan suatu reputasi yang dimiliki seseorang yang memungkinkan ia bisa memperoleh uang, barang-barang atau tenaga kerja, dengan jalan menukarkannya dengan suatu perjanjian untuk membayarnya disuatu waktu yang akan datang" (Firdaus dan Ariyanti, 2009:2).

KPR atau Kredit Pemilikan Rumah merupakan salah satu jenis pelayanan kredit yang diberikan oleh bank kepada para nasabah yang menginginkan pinjaman khusus untuk memenuhi kebutuhan dalam pembangunan rumah atau renovasi rumah (Hardjono, 2008:25). KPR suatu fasilitas kredit yang diberikan oleh perbankan kepada para nasabah perorangan yang akan membeli atau memperbaiki rumah (Bank Indonesia, 2011). KPR merupakan salah satu bentuk dari kredit konsumer yang dikenal pula dengan housing loan, pemberian fasilitas ini untuk konsumen yang memerlukan papan, digunakan untuk kepentingan pribadi keluarga atau rumah tangga, tidak ditujukan untuk yang bersifat komersial dan tidak memiliki pertambahan nilai barang atau jasa di masyarakat (Nasrun, 2012:14).

Laporan keuangan merupakan laporan yang dirancang untuk para pembuat keputusan, terutama pihak di luar perusahaan, mengenai posisi keuangan dan hasil usaha perusahaan.. Soemarso (2005:34). Laporan keuangan yang menggambarkan hasil dari proses akuntansi yang digunakan sebagai alat komunikasi untuk pihak-pihak yang berkepentingan dengan data keuangan atau aktifitas perusahaan (Sundjaya, 2006:47). Laporan keuangan merupakan bagian dari proses pelaporan keuangan. Laporan keuangan yang lengkap biasanya meliputi neraca, laporan laba rugi, laporan perubahan posisi keuangan (yang dapat disajikan dalam berbagai cara seperti misalnya sebagai laporan arus kas atau laporan arus dana), catatan dan laporan lain, serta materi penjelasan yang merupakan bagian integral dari laporan keuangan" (Ikatan Akuntan Indonesia, 2009:1)

\section{Kajian Pustaka}

Analisis rasio rentabilitas merupakan suatu rasio yang digunakan untuk mengukur efisiensi usaha untuk memperoleh laba semaksimal mungkin (Jumingan, 2011:122). Rentabilitas suatu perusahaan menunjukkan perbandingan antara laba dengan aktiva atau modal yang menghasilkan laba tersebut. Dengan kata lain rentabilitas adalah kemampuan suatu perusahaan untuk menghasilkan laba selama periode tertentu (Prastowo, 2008:90). Rentabilitas adalah hasil perolehan dari investasi (penanaman modal) yang dikatakan dengan persentase dari besarnya investasi”" (Veithzal. dkk., 2007:720)

Menurut Veithzal. dkk. (2007:720) Faktor rentabilitas antara lain dilakukan melalui penilaian terhadap komponen-komponen berikut:

\section{ROA (Return On Asset)}

ROA (return on asset) adalah kemampuan perusahaan dalam memanfaatkan aktivanya untuk memperoleh laba. Rasio ini mengukur tingkat kembalian investasi yang telah dilakukan oleh perusahaan dengan menggunakan seluruh dana (aktiva) yang dimilikinya. Rasio ini dapat di bandingkan dengan tingkat bunga bank yang berlaku. Rumus yang dipergunakan adalah: 


$$
\text { ROA }=\frac{\text { Laba sebelum pajak }}{\text { Rata-rata total asset }} \times 100 \%
$$

Semakin besar ROA, berarti semakin besar pula tingkat keuntungan yang dicapai dari semakin baiknya posisi bank dari segi penggunaan assetnya.

\section{ROE ( Return On Equity)}

Merupakan indikator yang sangat penting bagi para pemegang saham dan calon investor untuk mengukur kemampuan bank dalam memperoleh laba bersih yang dikaitkan dengan pembayaran deviden. Rumus yang digunakan adalah:

$$
\mathrm{ROE}=\frac{\text { Laba setelah pajak }}{\text { Rata-rata Equity }} \times 100 \%
$$

Apabila terjadi kenaikan dalam rasio ini, berarti terjadi kenaikan laba bersih dari bank yang bersangkutan kenaikan ini menyebabkan naiknya harga saham bank, yang akan membuat para pemegang sahan bank dan para investor di pasar modal ingin membeli saham bank tersebut.

\section{3. $\quad$ NIM (Net Interest Margin)}

Rasio ini menunjukan kemampuan earning assets dalam menghasilkan pendapatan bunga. Rumus yang digunakan adalah:

$$
\mathrm{NIM}=\frac{\text { Pendapatan Bunga Bersih }}{\text { Rata-rata Aktiva Produktif }} \times 100 \%
$$

NIM harus cukup besar untuk menutupi kerugian-kerugian pinjaman, kerugian-kerugian sekuritas dan pajak untuk dijadikan profit dan meningkatkan pendapatan.

\section{Metode Penelitian}

Penelitian ini menggunakan penelitian kualitatif dengan studi kasus, dengan objek penelitian adalah persepsi informan Accounting, Finance, Treasury, dan Marketing.

\section{Teknik Pengumpulan Data}

Dalam pengambilan informasi, obyek penelitian di ambil sesuai dengan kriteria data yang diperlukan dan di butuhkan oleh peneliti sendiri. Dimana kriteria tersebut menjadi sebuah sampel dalam penelitian sebagai berikut: Pengambilan sampel yang memperhatikan pertimbangan unsur-unsur atau kategori dalam populasi penelitian. Seperti Aspek Keuangan, yaitu meliputi perhitungan ROA, Laba Sebelum pajak, Rata- rata total asset. ROE yang merupakan indikator yang sangat penting untuk para pemegang saham dan calon investor untuk mengukur kemampuan bank dalam memperoleh laba bersih. NIM (Net Interest Margin), menunjukkan kemampuan earning asset dalam menghasilkan pendapatan bunga, dimana indikator yang 
dibutuhkannya adalah pendapatan bunga bersih, dan rata- rata aktiva produktif. BOPO, perbandingan antara biaya variabel operasional dengan pendapatan operasional dalam mengukur tingkat efisiensi dan kemampuan bank dalam melakukan kegiatan operasional, indikator yang dibutuhkan antara lain, total beban operasional dan total pendapatan operasional.

\section{Teknik Analisis Data}

Pengambilan sampel dengan menetapkan ciri yang sesuai dengan tujuan. Seperti aspek teoritis, yang meliputi keterkaitan obyek yang diteliti dengan teori - teori perpajakan yang berlaku untuk menghindari kesalahan penyajian. Data Rekap laporan keuangan pada bank BTN. Melakukan Grand Tour dengan cara wawancara kepada bagian Finance, Treasury, Accounting dan Manager.Hal ini dilakukan sebagai salah satu sahnya persyaratan dalam metodologi penelitian kualitatif dengan studi kasus.

Teknik sampel digunakan adalah sebagian dari jumlah dan karakteristik yang dimiliki oleh populasi. Dimana kriteria tersebut menjadi sebuah sampel dalam penelitian sebagai berikut :

1. Data perusahaan yang meliputi laporan keungan laba/rugi , Neraca, dan laporan posisi keuangan bank BTN

2. Data laporan keuangan $2013-2016$

3. Laporan keuangan $2013-2016$

4. Mewawancarai staf perusahaan yang berkaitan langsung dengan peneliti seperti bagian Accounting, finance, Treasury, Manager.

\section{Pembahasan Hasil}

Penelitian dilakukan pada bagian Accounting, Finance, Treasury, dan Marketing pada bank BTN (Persero), Tbk. Intervensi peneliti terhadap jawaban informan dihindari sehingga diperoleh pendapat yang asli. Sebanyak 10 informan yang diwaancarai mengenai persepsi mereka mengenai Kredit KPR. Laporan Keuangan yang terkait dengan rasio Rentabilitas. Rangkuman jawaban informan dikelompokkan menjadi 5 bahagian yaitu: perhitungan realisasi kredit, perhitungan rasio rentabilitas yang terdiri atas: ROA (Return On Asset), ROE (Return on Equity), NIM (NET Interest Margin) dan BOPO (By Operasional),

\section{Realisasi Kredit}

Tabel 1. Realisasi Kredit

Periode 31 desember 2013 sampai 31 desember 2015

(Dalam Persentase)

\begin{tabular}{|c|c|c|c|c|c|c|c|c|c|}
\hline Keterangan & $\mathbf{2 0 1 3}$ & Naik & Turun & $\mathbf{2 0 1 4}$ & Naik & Turun & $\mathbf{2 0 1 5}$ & Naik & Turun \\
\hline Konsumer & $106 \%$ & - & - & $73 \%$ & - & $33 \%$ & $131.39 \%$ & $58.39 \%$ & - \\
\hline Komersial & $76 \%$ & - & - & $60 \%$ & - & $16 \%$ & $89.74 \%$ & $29.74 \%$ & - \\
\hline Realisasi & $90 \%$ & - & - & $67 \%$ & - & $23 \%$ & $92.83 \%$ & $25.83 \%$ & - \\
\hline
\end{tabular}




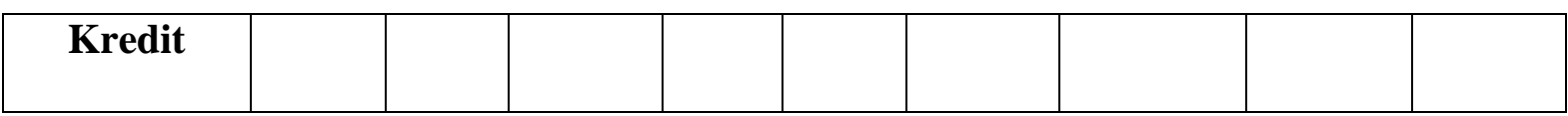

Sumber: Data diolah, 2017

Berdasarkan tabel III.1 diatas dapat diketahui bahwa pada tahun 2013 realisasi kredit senilai 90\%, dan terjadi penurunan sebesar 23\% pada tahun 2014 sehingga realisasi kredit di tahun 2014 senilai 67\%. Pada tahun 2015 terjadi kenaikan realisasi kredit sebesar $25.83 \%$ sehingga realisasi kredit di tahun 2015 senilai $92.83 \%$.

ROA (Return On Asset)

Tabel 2. Rasio ROA (Return On Asset)

Periode 31 desember 2013 sampai 31 desember 2015

(Dalam Milliaran Rupiah)

\begin{tabular}{|c|c|c|c|}
\hline $\begin{array}{c}\text { Komponen Rasio ROA } \\
\text { (Return On Asset) }\end{array}$ & $\mathbf{2 0 1 3}$ & $\mathbf{2 0 1 4}$ & $\mathbf{2 0 1 5}$ \\
\hline Laba sebelum pajak & 2.140 .771 & 1.548 .172 & 2.541 .886 \\
\hline Rata-rata Total Asset & 131.169 .730 & 144.575 .961 & 171.807 .592 \\
\hline Total ROA (dalam \%) & $\mathbf{1 . 6 3 \%}$ & $\mathbf{1 . 0 7 \%}$ & $\mathbf{1 . 4 7 \%}$ \\
\hline
\end{tabular}

Sumber : Data diolah, 2017

Dari tabel diatas juga dapat diketahui Total Aset terbesar Bank BTN terdapat pada tahun 2015 yaitu sebesar 171.807.592, sedangkan Total Aset terendah Bank BTN terdapat pada tahun 2013 yaitu sebesar 131.169.730. Dari tabel diatas juga dapat diketahui besarnya ROA Bank BTN pada periode 2013 sampai dengan 2015, dan diketahui ROA terbesar Bank BTN terdapat pada tahun 2013 yaitu sebesar $1.63 \%$, sedangkan ROA terendah Bank BTN terdapat pada tahun 2014 yaitu sebesar $1.07 \%$.

ROE ( Return On Equity)

Tabel 3. Rasio ROE (Return On Equity)

Periode 31 desember 2013 sampai 31 desember 2015

(Dalam Milliaran Rupiah )

\begin{tabular}{|c|c|c|c|}
\hline $\begin{array}{c}\text { Komponen Rasio ROE } \\
\text { (Return On Equity) }\end{array}$ & $\mathbf{2 0 1 3}$ & $\mathbf{2 0 1 4}$ & $\mathbf{2 0 1 5}$ \\
\hline Laba setelah pajak & 1.443 .057 & 1.115 .625 & 1.811 .337 \\
\hline Rata-rata Equity & 11.556 .753 & 12.206 .406 & 13.860 .107 \\
\hline Total ROE (dalam \%) & $\mathbf{1 2 . 5 0 \%}$ & $\mathbf{9 . 1 3} \%$ & $\mathbf{1 3 . 0 8 \%}$ \\
\hline
\end{tabular}

Sumber: Data diolah, 2017

Dari tabel diatas juga dapat diketahui Rata-rata Equity terbesar Bank BTN terdapat pada tahun 2015 yaitu sebesar 13.860.107, sedangkan Rata-rata Equity terendah Bank BTN terdapat pada tahun 2013 yaitu sebesar 11.556.753. Dari tabel diatas juga dapat diketahui besarnya ROE Bank BTN pada periode 2013 sampai dengan 2015, dan diketahui ROE terbesar Bank BTN terdapat pada tahun 2015 yaitu sebesar $13.08 \%$, sedangkan ROE terendah Bank BTN terdapat pada tahun 2014 yaitu sebesar $9.13 \%$. 
IJBE: Integrated Journal of Business and Economics

e-ISSN: 2549-3280

NIM (Net Interest Margin)

Tabel 4. Rasio NIM (Net Interest Modal)

Periode 31 desember 2013 sampai 31 desember 2015

( Dalam Milliaran Rupiah )

\begin{tabular}{|c|c|c|c|}
\hline $\begin{array}{c}\text { Komponen Rasio NIM } \\
\text { (Net Interest Margin) }\end{array}$ & $\mathbf{2 0 1 3}$ & $\mathbf{2 0 1 4}$ & $\mathbf{2 0 1 5}$ \\
\hline Pendapatan bunga bersih & 5.653 .323 & 5.464 .581 & 6.811 .076 \\
\hline Rata-rata Aktiva Produktif & 103.571 .051 & 122.557 .185 & 132.398 .433 \\
\hline Total NIM (dalam \%) & $\mathbf{5 . 4 5 \%}$ & $\mathbf{4 . 4 5 \%}$ & $\mathbf{5 . 1 4} \%$ \\
\hline
\end{tabular}

Sumber: Data diolah, 2017

Dari tabel diatas juga dapat diketahui Rata-rata Aktiva Produktif tebesar Bank BTN terdapat pada tahun 2015 yaitu sebesar 132.398.433, sedangkan Rata-rata Aktiva Produktif terendah Bank BTN terdapat pada tahun 2013 yaitu sebesar 103.571.051. Dari tabel diatas juga dapat diketahui besarnya NIM Bank BTN pada periode 2013 sampai dengan 2015, dan diketahui NIM terbesar Bank BTN terdapat pada tahun 2013 yaitu sebesar $5.45 \%$, sedangkan NIM Bank BTN terendah terdapat pada tahun 2014 yaitu sebesar $4.45 \%$.

BOPO (Biaya Operasional)

Tabel 5. Rasio BOPO (Beban Operasional)

Periode 31 desember 2013 sampai 31 desember 2015

( Dalam Milliaran Rupiah )

\begin{tabular}{|l|c|c|c|}
\hline $\begin{array}{c}\text { Komponen Rasio BOPO } \\
\text { (Biaya Operasional) }\end{array}$ & $\mathbf{2 0 1 3}$ & $\mathbf{2 0 1 4}$ & $\mathbf{2 0 1 5}$ \\
\hline Total Beban Operasional & 9.859 .630 & 12.752 .550 & 3.295 .986 \\
\hline Total Pendapatan Operasional & 11.995 .539 & 14.298 .763 & 3.853 .712 \\
\hline Total BOPO (dalam \%) & $\mathbf{8 2 . 1 9 \%}$ & $\mathbf{8 9 . 1 9 \%}$ & $\mathbf{8 5 . 5 3 \%}$ \\
\hline
\end{tabular}

Sumber: Data diolah, 2017

Dari tabel diatas juga dapat diketahui Total Pendapatan Operasional tebesar Bank BTN terdapat pada tahun 2014 yaitu sebesar 14.298.763, sedangkan Total Pendapatan Operasional terendah Bank BTN terdapat pada tahun 2015 yaitu sebesar 3.853.712. Dari tabel diatas juga dapat diketahui besarnya BOPO Bank BTN pada periode 2013 sampai dengan 2015, dan diketahui BOPO terbesar Bank BTN terdapat pada tahun 2014 yaitu sebesar 89.19\%, sedangkan BOPO Bank BTN terendah terdapat pada tahun 2013 yaitu sebesar $82.19 \%$.

\section{Analisa Perkembangan}

Pada analisa perkembangan kinerja laporan keuangan periode 31 desember 2013 sampai 31 desember 2015 pada PT. Bank BTN dapat dilihat pada tabel rasio sebagai berikut:

Tabel 6. Perkembangan Rasio Rentabilitas Menurut Standar BI Periode 31 desember 2013 sampai 31 desember 2015

(Dalam milliaran rupiah ) 
IJBE: Integrated Journal of Business and Economics e-ISSN: 2549-3280

\begin{tabular}{|c|c|c|c|c|c|}
\hline \multirow[t]{2}{*}{ Rasio } & \multicolumn{3}{|c|}{ Tahun } & \multirow{2}{*}{ Standar BI } & \multirow{2}{*}{ Ket } \\
\hline & 2013 & 2014 & 2015 & & \\
\hline ROA & $1.63 \%$ & $1.07 \%$ & $1.47 \%$ & $\begin{array}{l}0,5 \%-1,25 \% \text { ( jika hasil rasio } \\
\text { ini lebih tinggi maka } \\
\text { dikatakan perolehan laba } \\
\text { sangat tinggi). }\end{array}$ & $\begin{array}{l}\text { Perolehan laba } \\
\text { sangat tinggi }\end{array}$ \\
\hline ROE & $12.50 \%$ & $9.13 \%$ & $13.08 \%$ & $\begin{array}{l}5 \%-12,5 \% \text { ( jika hasil } \\
\text { rasionya di lebih besar maka } \\
\text { dikatakan perolehan laba } \\
\text { sangat tinggi). }\end{array}$ & $\begin{array}{l}\text { Perolehan laba } \\
\text { sangat tinggi }\end{array}$ \\
\hline NIM & $5.45 \%$ & $4.45 \%$ & $5.14 \%$ & $\begin{array}{l}\text { 1,5\%-2\% ( jika hasil rasio ini } \\
\text { diatasnya maka dikatakan } \\
\text { margin bunga bersih sangat } \\
\text { tinggi). }\end{array}$ & $\begin{array}{l}\text { Margin bunga } \\
\text { bersih sangat } \\
\text { tinggi }\end{array}$ \\
\hline BOPO & $82.19 \%$ & $89.19 \%$ & $85.53 \%$ & $\begin{array}{l}\leq 94 \% \text { (jika hasil rasio ini } \\
\text { dbawahnya maka dikatakan } \\
\text { semakin efisien biaya } \\
\text { operasional bank). }\end{array}$ & $\begin{array}{l}\text { Biaya operasional } \\
\text { sangat tinggi }\end{array}$ \\
\hline
\end{tabular}

Sumber : Laporan Tahunan PT.Bank BTN ( Bank Tabungan Negara )

\section{Kesimpulan}

Dari hasil pembahasan pada bab sebelumnya, maka dapat disimpulkan sebagai berikut :Semakin meningkatnya rentabilitas maka semakin baik perusahaan dalam memperoleh kenaikan laba bersih dan semakin baik pula perusahaan dalam pemberian kredit.Semakin rendahnya biaya operasional perusahaan, maka semakin efisien bank dalam kegiatan operasionalnya.Keberhasilan bank BTN pada tahun 2013 sampai dengan 2015 dapat dikatakan berhasil karena kondisi rentabilitas dan realisasi kredit yang meningkat sesuai dengan ketetapan SE BI No. 6/23/DPNP 2004.Dalam segi KPR (Kredit Pemilikan Rumah), bank BTN mampu menjadi pesaing dalam dunia perbankan.

\section{Referensi}

Arianti, M. dan Firdaus, R. (2009). Manajemen Perkreditan Bank Umum. Alfabeta

Budisantoso, T dan Sigit. (2006). Bank dan Lembaga Keuangan Lain. Edisi 2. Jakarta: Salemba Empat

Haroen, N. (2012). Pembiayaan Musyarakah dari segi KPR. Jakarta: Lembaga Penerbit Fakultas Ekonomi

Hasibuan, M. SP. 2005. Dasar-dasar Perbankan . Jakarta: PT. Bumi Aksara

Ikatan Akuntansi Indonesia. (2009). Standar Akuntansi Indonesia. Jakarta: Salemba Empat

Jumingan. (2011). Analisis Laporan Keuangan. Jakarta: PT. Bumi Aksara 
IJBE: Integrated Journal of Business and Economics e-ISSN: 2549-3280

Kasmir. (2012). Bank dan Lembaga Keuangan Lainnya. Jakarta: PT. Raja Grafindo Persada

Muljono, P. T. (2007). Manajemen Perkreditan bagi Bank komersil. Yogyakarta: Liberty

Prastowo, D. (2008). Analisis Laporan Keuangan. Yogyakarta: Unit Penerbit dan Percetakan YKPN

Rivai, V. (2007). Bank dan Financial Institution Management. Jakarta: PT. Raja Grafindo

Sastrohamidjojo, H. (2008). Mudah Memiliki Rumah Idaman Lewat KPR. Jakarta: Galang Press

Supriyono, M. (2011). Buku Pintar Perbankan. Jakarta: Andi Publisher 